\title{
Solidification analysis in permanent mould casting of aluminium alloy LM6 reinforced titanium carbide particulates metal matrix composites
}

\begin{abstract}
Permanent mould casting was used as the production technique to produce the metal matrix composites (MMCs) specimens. Thermal measurements during the casting process were recorded. Based on these data, solidification graphs were plotted to understand the solidification characteristics. Solidification analysis was performed by interpreting the parameters drawn from the solidification graphs. Parameters such as; nucleation primary alpha phase temperature, liquidus arrest temperature, eutectic growth temperature and solidification time were identified. The results showed that addition of titanium carbide particulates (TiCp) into the aluminium-11.8\% silicon alloy (LM6) have affected various time and temperature parameters of its solidification properties. These in turn will have an influence on the mechanical property of the MMCs.
\end{abstract}

Keyword: Aluminium alloy LM6; Casting; Metal matrix composites; Permanent mould; Solidification; Titanium carbide particulates 